\title{
Ecological Characteristics of Ventenata dubia in the Intermountain Pacific Northwest
}

\author{
John M. Wallace, Pamela L. S. Pavek, and Timothy S. Prather*
}

\begin{abstract}
Ventenata dubia is an exotic winter annual grass that has invaded Conservation Reserve Program (CRP) lands, improved pastures, intensively managed hay fields, and rangelands within the Intermountain Pacific Northwest (PNW). Currently, producers are attempting to develop V. dubia management strategies with little knowledge of its life history traits. We conducted several studies to characterize $V$. dubia life history patterns. Preliminary germination trials were completed to describe primary and secondary dormancy characteristics. Field studies were conducted to evaluate (1) seed bank persistence patterns, (2) seedling emergence patterns under $V$. dubia litter, and (3) seedling emergence and phenological development patterns within timothy hay, CRP, and rangeland habitats. Preliminary germination trials suggest that the after-ripening period required for loss of dormancy does not exceed $30 \mathrm{~d}$ and that dormancy breakdown peaks at approximately $90 \mathrm{~d}$, after which germination occurs over a wide range of temperatures (9 to $29 \mathrm{C}$ ). A small fraction $(<1 \%)$ of the seed bank remained germinable up to $3 \mathrm{yr}$ after burial at $2 \mathrm{~cm}$ depth in a grassland habitat. Seedling emergence and survival was significantly greater under high $V$. dubia litter layers (100\% cover) compared with bare surface during the drier study year because of higher soil moisture levels maintained under litter. Across habitat types, mean seedling emergence (50\% of total) occurred between 33 and 94 growing degree days (GDD) after soil moisture rose above the permanent wilting point in the fall. Seedling emergence periodicity varied among habitat types in relation to spring seedling emergence, ranging from 0 to $13 \%$ of total emergence per year. Phenological development differed across sites and years by up to several hundred GDDs but was closely aligned to Julian days. This collection of studies improves our understanding of $V$. dubia life history traits and will aid integrated weed management strategies in the Intermountain PNW.
\end{abstract}

Nomenclature: North Africa grass, Ventenata dubia (Leers) Coss.; timothy, Phleum pratense L.

Key words: Exotic winter annual, germination, life history traits, phenology, seedling emergence.

Ventenata dubia (Leers) Coss., referred to as wire grass or North Africa grass, is a winter annual grass in the Aveneae tribe that invades several ecosystems within the Intermountain Pacific Northwest (PNW), a region that encompasses the areas of Washington, Oregon, and Idaho between the Rocky Mountains to the east and the Cascade Range to the west (Pavek et al. 2011). In the past decade, $V$. dubia populations have rapidly expanded in perennial grass systems with varying disturbance regimes. Ventenata

DOI: $10.1614 /$ IPSM-D-14-00034.1

* First and third authors: Research Support Scientist and Professor, Plant, Soil, and Entomological Department, University of Idaho, Moscow, ID 83844; second author: Agronomist, USDANRCS-Pullman Plant Materials Center, Pullman, WA 99164. Current address of first author: Plant Science Department, Pennsylvania State University, University Park, PA 16802. Corresponding author’s E-mail: jmw309@psu.edu dubia has become increasingly problematic in intensively managed grass-hay production systems. Timothy (Phleum pratense L.) hay producers have altered harvest schedules, crop rotations, and other cultural strategies to avoid significant losses to export markets that result from $V$. dubia hay infestation (Fountain 2011). Ventenata dubia can also displace mixed stands of caespitose and rhizomatous perennial forage grasses in improved pastures that vary in grazing regimes, as well as Conservation Reserve Program (CRP) lands that are comparatively less disturbed after establishment (Wallace and Prather 2011). Ventenata dubia populations have also expanded in rangeland habitats, including the Snake River canyon grasslands (McCloskey et al. 2011) and sagebrush steppe (Butler 2011), where it has increased in areas previously dominated by Bromus tectorum L. and Taeniatherum caput-medusae (L.) Nevski. Finally, V. dubia is one of the primary invasion threats to intact Palouse Prairie remnants 


\section{Management Implications}

Ventenata dubia is an exotic annual grass that has invaded established CRP lands, improved pastures, intensively managed hay fields, and rangelands within the Intermountain PNW. Significant economic and ecological impacts have resulted from $V$. dubia invasions across perennial grass habitats in recent years, underscoring the need for development of integrated control strategies. Control of $V$. dubia using selective herbicides within perennial grass stands, as well as cultural control strategies, will benefit from greater understanding of $V$. dubia life history patterns.

Within the Intermountain PNW, $V$. dubia seedling emergence occurs after fall rains have increased soil moisture above the PWP in timothy hay, CRP, and rangeland habitats. The greatest proportion of fall seedling emergence occurs within $6 \mathrm{wk}$ of initial emergence. Spring seedling emergence is more likely in timothy hay and rangeland habitats where fall environmental conditions are less conducive for seedling emergence and survival in the Intermountain PNW. At a local scale, seedling emergence and survival is likely mediated by the amount of residue at the soil surface. Higher $V$. dubia litter levels will increase seedling emergence and survival compared with bare surface during drier or colder fall growing seasons. A small fraction of $V$. dubia seed banks $(<1 \%)$ may remain persistent, or germinable, for up to $3 \mathrm{yr}$ at shallow soil depths $(2 \mathrm{~cm})$.

These life history traits should inform $V$. dubia management strategies in the Intermountain PNW. Ventenata dubia may be controlled with early postemergence herbicide applications in late fall. However, this application timing is often a narrow window for growers because of unpredictable weather conditions. Predictive models of seedling emergence patterns can be used to time preemergent or early postemergent applications to temperature and soil moisture conditions. Additional research is needed to identify herbicide control options for fall applications that could potentially provide soil residual control of spring-emerged seedlings. Predictive models of phenological development may also be used to time cultural control strategies that aim to reduce or prevent $V$. dubia seed production, such as targeted mowing in CRP or altering hay harvest schedules. Cultural control strategies that target the seedling phase of $V$. dubia's life cycle should focus on litter management techniques, such as prescribed burning, to eliminate the benefits of litter on seedling recruitment. Because of low levels of seed bank persistence, integrative control strategies should be planned for several years $(>3 \mathrm{yr})$ to reduce the negative effects of $V$. dubia on managed perennial grass systems across the Intermountain PNW.

located in eastern Washington and northern Idaho (Nyamai et al. 2011; Xu et al. 2013).

Ventenata dubia is native to southern Europe and northern Africa and has been present in the Intermountain PNW since at least the 1950s (Barkworth 1993). It remained a weed of little economic or ecological importance until recently. Consequently, little is known about its biology. Several traits likely contribute to V. dubia invasiveness in habitats across the Intermountain PNW. Field observations suggest that $V$. dubia primarily germinates in the fall and is thus preadapted to the Mediterranean climate of the Intermountain PNW.
Preliminary laboratory experiments of $V$. dubia seed biology were conducted in the mid-1980s using populations from the Palouse region of eastern Washington and northern Idaho (Northam and Callihan 1985; Patton et al. 1985). These studies indicated that $V$. dubia required an after-ripening period of approximately 2 mo before dormancy breakdown and that cold stratification treatments at $8 \mathrm{C}$ did not influence germination rates of nondormant seeds (Patton et al. 1985). Nondormant $V$. dubia seeds germinated across a wide range of temperatures (8 to $28 \mathrm{C}$ ), and compared with B. tectorum and T. caputmedusae, germination rates were comparatively lower at $8 \mathrm{C}$ and higher at $28 \mathrm{C}$ (Northam and Callihan 1985). Ventenata dubia produces slim, erect culms and matures rapidly in early summer. It also has moderately high levels of silica content $(\sim 2.7 \%)$, rendering it poor forage, as producer observations suggest (Pavek et al. 2011). Similar to Avena fatua L., its seed has a bent and twisted awn that aids local dispersal via "self burial" into the soil profile and long-distance dispersal via attachment to animals, equipment, or contaminated hay (Sharma and Vanden Born 1978).

Currently, development of $V$. dubia management strategies is slowed by our incomplete understanding of its ecological characteristics in the Intermountain PNW. Knowledge of life history patterns, particularly seedling emergence and phenological development, is essential for identifying the critical period of weed control (Knezevic et al. 2002) and for implementation of integrated pest management strategies (Swanton et al. 2008). Seedling emergence patterns are a function of complex factors that regulate dormancy and germination; these factors include genotypic variation among individuals and populations, maturation and postmaturation environments, and the germination environment (Meyer et al. 1997). In general, maternal environmental effects can produce phenotypic variation in life history traits among genetically similar individual plants or populations (Roach and Wulff 1987). Environmental factors that regulate seedling emergence and survival vary at local to ecosystem scales. At a local scale, such factors as burial depth (Harper 1977) and surface residue characteristics (Facelli 1991) can significantly influence seedling emergence patterns through several direct and indirect processes. At an ecosystem scale, life history traits may vary among habitats characterized by different climatic patterns and disturbance regimes. Examining the amplitude of variation in life history traits among habitats may elucidate which traits respond to selection and how such traits facilitate invasion processes (Mack and Pyke 1983). The perennial grass habitats invaded by $V$. dubia vary considerably in management intensity and encompass a range of environments that differ primarily in the amount and seasonal distribution of precipitation. 


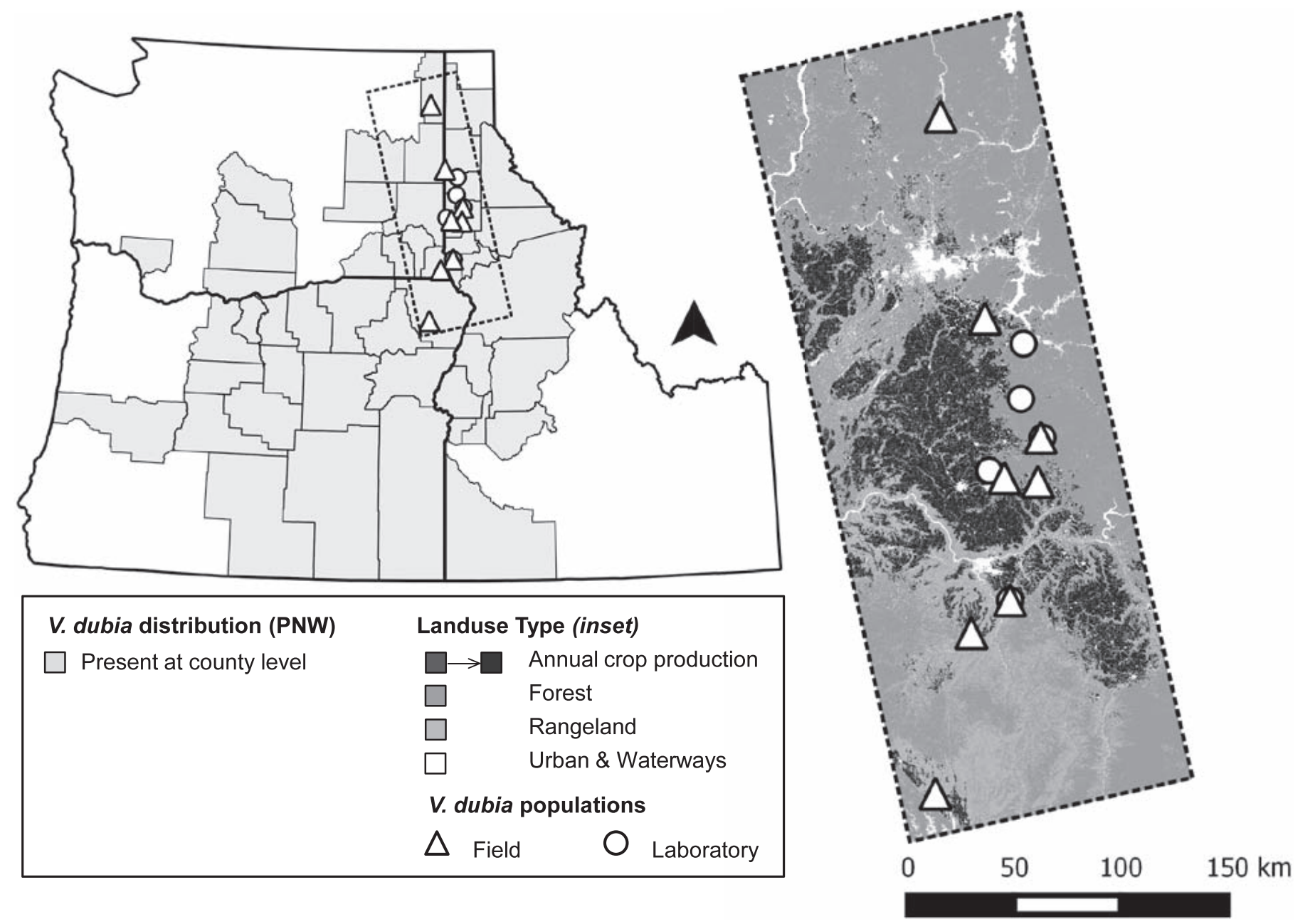

Figure 1. Locations of Ventenata dubia populations used for laboratory (in vitro) germination experiments and field studies of seedling emergence and phenological development patterns. Ventenata dubia populations were distributed across predominant land use types (USDA-NASS 2013) in the study region. The study region is presented in relation to 2013 county-level V. dubia distribution in the Pacific Northwest generated through U.S. Department of Agriculture Natural Resources Conservation Service surveys.

In this paper, we evaluated $V$. dubia life history traits through a series of laboratory and field studies, primarily focusing on factors that underlie seedling emergence patterns. We first conducted in vitro germination experiments that replicated and expanded on the dormancy and germination studies of Northam and Callihan (1985) and Patton et al. (1985) to inform field studies that observed life history patterns. We conducted a field study to determine seed bank persistence patterns to characterize the potential longevity of $V$. dubia in the seed bank. We also conducted a field experiment that evaluated $V$. dubia seedling emergence and survival patterns under varying levels of $V$. dubia litter to understand the direct and indirect effects of litter residue on environmental factors that influence seedling emergence and survival. Finally, we evaluated seedling emergence and phenological development patterns for $2 \mathrm{yr}$ within timothy hay, CRP, and rangeland habitats to evaluate how $V$. dubia life history patterns vary in habitats that differ in management intensity and prevailing environmental conditions. This collection of laboratory and field studies represents the most current knowledge of $V$. dubia life history traits in the Intermountain PNW.

\section{Materials and Methods}

Study Region. We conducted laboratory and field experiments using $V$. dubia populations from a $300-\mathrm{km}$ latitudinal gradient that encompassed parts of eastern Washington, northeastern Oregon, and northern Idaho (Figure 1). Although $V$. dubia is present throughout a greater extent of the PNW, producer surveys (unpublished data) and road surveys (Pavek et al. 2011) indicate that $V$. dubia invasion impacts have been most significant in the 
Table 1. Land use and habitat descriptions for $V$. dubia populations used in in vitro germination experiments and field studies focusing on seedling emergence and phenological development patterns. Habitat descriptions include dominant perennial grass species in parentheses.

\begin{tabular}{|c|c|c|}
\hline Ventenata dubia population & Land use $^{a}$ & Habitat description \\
\hline \multicolumn{3}{|c|}{ In vitro germination: After-ripening, cold stratification, and seed aging } \\
\hline Pullman, WA & Noncrop & Noncropland (Festuca ovina) \\
\hline \multicolumn{3}{|c|}{ In vitro germination: Temperature } \\
\hline Plummer, ID & Forest & Open forest understory (Pinus ponderosa habitat type) \\
\hline Sanders, ID & Pasture & Mixed grass stand (Poa secunda, Bromus inermis, Elymus trachycaulus) \\
\hline Harvard, ID & Hay & Timothy (Phleum pratense) monoculture \\
\hline Moscow, ID & CRP & Mixed grass stand (Alopecurus pratensis, Bromus marginatus) \\
\hline Lewiston, ID & Range & Early seral bunchgrass (Pseudoroegneria spicata habitat type) \\
\hline \multicolumn{3}{|c|}{ Seedling emergence and phenological development } \\
\hline Usk, WA (2012-2013) & Hay & Timothy (Phleum pratense) monoculture \\
\hline Harvard, ID (2012-2013) & Hay & Timothy (Phleum pratense) monoculture \\
\hline Worley, ID (2012) & CRP & Mixed grass stand (Bromus inermis, Thinopyrum intermedium) \\
\hline Deary, ID (2013) & CRP & Monoculture (Dactylis glomerata) \\
\hline Moscow, ID (2012-2013) & CRP & Monoculture (Thinopyrum intermedium) \\
\hline Enterprise, OR (2012) & Range & Late seral bunchgrass (Festuca idahoensis habitat type) \\
\hline Lewiston, ID (2013) & Range & Early seral bunchgrass (Pseudoroegneria spicata habitat type) \\
\hline Anatone, WA (2012-2013) & Range & Late seral bunchgrass (Pseudoroegneria spicata habitat type) \\
\hline
\end{tabular}

${ }^{a}$ CRP, Conservation Reserve Program.

study region. The study region includes the intermediate (30 to $45 \mathrm{~cm}$ ) and high $(45$ to $60 \mathrm{~cm}$ ) precipitation zones of the Columbia Plateau, which are dominated by dryland annual cropping. At a regional scale, these annual croplands interface with forested ecosystems to the northeast and canyon grassland ecosystems to the southwest (Figure 1). At a landscape scale, variation in topography and seasonal precipitation patterns contribute to a matrix of land use types in which perennial grass systems are embedded.

In Vitro Germination Trials. To inform field studies on V. dubia life history patterns, we replicated and extended previous research of Patton et al. (1985) and Northam and Callihan (1985), which determined the effects of afterripening, cold stratification, seed aging, and temperature on $V$. dubia populations located in the Palouse region.

Effects of After-Ripening, Cold Stratification, and Seed Aging on Germination. In the fall of 2009, we initiated studies to evaluate the effects of cold stratification and seed aging using seed collected from a natural infestation near Pullman, WA, in mid-July (Table 1). We initiated a study in 2013 to evaluate after-ripening requirements using seed collected on July 9 from the same area as the 2009 collections. In each case, seed were immediately separated from plants using a hammer mill and air screen seedcleaning machine, separated into 100-count batches, and dry-stored at $21 \mathrm{C}$. Germination of seed that was drystored for $0,30,60$, and $120 \mathrm{~d}$ after harvest was evaluated in 2013 to characterize after-ripening requirements. To determine the effects of cold stratification, we compared seed that was dry-stored for $4 \mathrm{mo}$ and then exposed to $5 \mathrm{C}$ for three durations $(0,5$, or $10 \mathrm{~d})$. Germination of seed dry-stored for $4,18,30$, and 42 mo was evaluated to characterize the influence of seed aging on seed viability and germination.

Each germination trial used similar methodology. Experimental treatments were replicated four times and arranged in a randomized complete block design using 100 viable seeds per replicate. Seeds were placed in a $150-\mathrm{mm}$ diam petri dish lined with Anchor ${ }^{\circledR}$ seed paper (Anchor Paper Company), which was kept moist with $1 \%$ bleach (6\% sodium hypochlorite) solution. Seed viability was evaluated using a forceps press test. Seed that collapsed under gentle pressure were discarded to avoid use of nongerminable seed in experiments. Germination was recorded for $70 \mathrm{~d}$ in growth chambers set at $18 \mathrm{C}$ and $14 \mathrm{~h}$ of daylight (Patton et al. 1985), and seed germination ( $>2 \mathrm{~mm}$ radicle) was recorded every 2 to $4 \mathrm{~d}$. Germinated seed were removed from the petri dish at the time of recording.

Effects of Temperature on Germination. In November 2010, we initiated a study to evaluate germination response of $V$. dubia seed, which were collected and dry-stored for 4 mo, 
to a range of constant temperatures (5.0 to $29.2 \mathrm{C}$ ). The study was conducted on $V$. dubia seed from populations located in five different habitats (forest, pasture, hay, CRP land, and rangeland) in the Intermountain PNW (Table 1; Figure 1). To complete the study, three experiments were performed sequentially on a temperature gradient bar (Holt and Orcutt 1996). Each experiment included five test temperatures (experiment 1: 5.0, 7.8, 8.6, 9.4, 11.3 C; experiment 2: 11.8, 12.2, 13.3, 15.8, 17.0 C; experiment 3: $21.5,23.3,25.6,27.3,29.2 \mathrm{C})$ that were monitored with insulated thermocouples. The experimental unit consisted of $25 \mathrm{~V}$. dubia seeds placed in $40-\mathrm{mm}$ petri dishes filled with moistened filter paper and covered with plastic lids sealed with Parafilm. Experimental units were replicated four times per temperature treatment. Test populations $(n=5)$ were arranged using a randomized complete block design at each test temperature across the gradient bar. Germination ( $>2-\mathrm{mm}$ radical visible) was recorded and seeds were removed every 2 to $4 \mathrm{~d}$. Seed mortality within petri dishes that resulted from pathogenic fungi was also recorded and similarly removed from petri dishes at the time of recording; seeds lost to pathogenic mortality were considered to be nongerminable. Each experiment was terminated at $42 \mathrm{~d}$.

Statistical Analyses. For each germination experiment, total cumulative germination (\%) was plotted against time (d), and nonlinear regression models were fitted to the data and analyzed using the form

$$
g=C /\left\{1+e\left[-b_{1}\left(d-b_{0}\right)\right]\right\}
$$

where $g$ is cumulative germination expressed as a percentage, $d$ is time in number of days, $C$ is total cumulative germination expressed as a percentage, and $b_{0}$ and $b_{1}$ are estimated parameters, in which $b_{0}$ estimates mean germination time (days to $50 \%$ germination of germinable seed) and $b_{1}$ is the rate (seeds $\mathrm{d}^{-1}$ ) at which germination occurs. To determine whether germination rates varied across a given set of treatments, we contrasted full and reduced models using the $F_{\mathrm{R}}$ test statistic from the residual sums of squares reduction test in PROC NLIN in SAS (Version 9.3, SAS Institute, Cary, NC). Total cumulative germination was specified in the model for temperature experiments because seed viability was not quantified across populations, which would confound curve-fitting comparisons if parameterized. For temperature experiments, total cumulative germination was analyzed separately by fitting general linear mixed models in SAS to examine population main effects by temperature with block as a random factor. Total cumulative germination was transformed using arcsine square root to achieve homogeneity of variance and was expressed as a percentage.

Seed Bank Persistence. In October 2009 we initiated a study to evaluate the effects of burial duration and depth on $V$. dubia seed bank persistence. The study was conducted on a south-facing slope with Palouse and Tucannon silt loam soil at the Natural Resources Conservation Service (NRCS) Pullman Plant Materials Center (PPMC) near Pullman, WA, and on a west-facing slope with Spokane loam soil on Paradise Ridge south of Moscow, ID. Both sites were infested with $V$. dubia and receive approximately $51 \mathrm{~cm}$ of annual precipitation. Ventenata dubia seeds collected in mid-July near Pullman, WA, were separated in 100-count batches and after-ripened for approximately 3 mo. Seed batches were placed in 10 by $10-\mathrm{cm}$ nylon mesh fabric packets containing $10 \mathrm{~cm}^{3}$ of sifted soil from the PPMC study site and buried on October 16 at the Paradise Ridge site and October 20 at the PPMC site. Burial depth (2 and $8 \mathrm{~cm})$ and burial duration $(1,13,25,37$, and $49 \mathrm{mo}$ ) treatments were arranged in a randomized complete block design with four replications. Replicates were located in natural $V$. dubia infestation patches within approximately 0.015 ha of each other.

Seed packets were exhumed and seeds with visible radicles $(>2 \mathrm{~mm})$ were counted as germinated. At the 1mo burial interval, nongerminated seed were subjected to a growth chamber germination assay to determine the germinable fraction of the seed bank. Seeds were surfacesterilized using a $5 \%$ bleach solution $(0.25 \%$ sodium hypochlorite) and placed on petri dishes $(150 \mathrm{~mm})$ lined with seed germination paper in a growth chamber set at $18 \mathrm{C}$ with $12 \mathrm{~h}$ of fluorescent light. Germination was recorded every $3 \mathrm{~d}$ for $60 \mathrm{~d}$. At subsequent burial intervals $(13,25,37$, and $49 \mathrm{mo})$, nongerminated seed were indiscernible from soil because of decay, eliminating the need for germination assays. Seed bank fate for each burial duration and depth was categorized as (1) germinated: seeds with visible radicles, (2) persistent: nongerminated seeds that germinated in the growth chamber, and (3) lost: seeds not found because of decay or nongerminated seed that did not germinate in the growth chamber.

The effect of seed burial depth on seed bank fate (germination, persistence, and loss) 1 mo after burial and seed bank persistence in subsequent years were analyzed by fitting general linear mixed models to examine the main effect of burial depth by burial duration with block and site as a random factor. Seed bank fate data were arcsine square roottransformed to achieve homogeneity of variance. Treatment means were separated using Fisher's LSD $(\mathrm{P}<0.05)$. Results are presented using untransformed treatment means.

Effects of Litter on Seedling Emergence. We conducted a garden experiment at the NRCS-PPMC in 2011-2012 and replicated it in 2012-2013 to evaluate the effect of $V$. dubia litter on $V$. dubia seedling emergence and survival from an artificial seed bank. In August 2011, V. dubia plants were collected from a local population and hand threshed. Additionally, foliar cover $(\%)$ was visually 
estimated, and V. dubia biomass (g) was collected in a random sample of 40 plots $\left(400 \mathrm{~cm}^{2}\right)$. Linear regression was performed to estimate $V$. dubia litter fresh weight $(\mathrm{g})$ that correlated to 33, 66, and $100 \%$ cover. Experimental treatments consisted of $100 \mathrm{~V}$. dubia seeds sown on the soil surface and four litter treatments corresponding to 0,33 , 66 , and $100 \% \mathrm{~V}$. dubia cover $\left(0,98,196\right.$, and $392 \mathrm{~g} \mathrm{~m}^{-2}$, respectively). In 2011, the experimental unit consisted of $0.05-\mathrm{m}^{2}$ pots. Tilled soil was hand-sifted in the field and used to fill the pots to within $5 \mathrm{~cm}$ of the pot edge, allowing for placement of litter within the pot and to protect litter from being windblown. Because of poor drainage within the pots after snow melt in late winter, wooden plot frames were used in replacement of pots in the 2012-2013 experiment.

The experiment was conducted with a 4 by 4 factorial treatment design arranged in a randomized complete block with four replications. Treatment levels included four litter levels $\left(0,98,196,392 \mathrm{~g} \mathrm{~m}^{-2}\right)$ and four harvest dates. Three harvests were scheduled approximately $2 \mathrm{wk}$ apart after germination in the fall growing season, and one harvest was scheduled for the spring growing season. Separate harvest dates allowed for destructive sampling of pots or frames to quantify seedling densities below the litter layer. Soil moisture (\% volumetric water content; VWC) and soil temperature (C) were monitored (5TM Soil Probe, Decagon Devices) at a $2-\mathrm{cm}$ depth in the 0, 98, and $392 \mathrm{~g} \mathrm{~m}^{-2}$ litter treatments during both years of the study in an extra litter treatment replicate that was located between experimental blocks. In the 2011-2012 experiment, final densities in several 196 and $392 \mathrm{~g} \mathrm{~m}^{-2}$ litter treatments exceeded 100 plants, raising concerns about seed contamination from the threshed litter. In 2012 2013, we included check plots with no sown seeds for each litter treatment. Litter treatments were rescaled $(23,44$, $64 \%$ for $98,196,392 \mathrm{~g} \mathrm{~m}^{-2}$, respectively) in both years to provide estimates of litter treatment effects for comparisons to the litter control. Ventenata dubia seedling density was quantified at each fall harvest date. Plant density, tillers per plant, and per capita seed production were quantified at the spring harvest date.

The effect of litter $\left(\mathrm{g} \mathrm{m}^{-2}\right)$ on seedling emergence and survival was analyzed by fitting a general linear mixed model to examine the main effect of litter level by harvest date and year with block as a random factor. The effect of litter levels on plant density, tillers per plant, and seed production were subjected to analysis of variance for 20122013. Data were natural $\log$-transformed to achieve homogeneity of variance. Treatment means were separated using Fisher's LSD $(\mathrm{P}<0.05)$. Results are presented using untransformed treatment means.

Seedling Emergence and Phenological Development Patterns. We monitored $V$. dubia seedling emergence and phenological development in field plots through the 20112012 and 2012-2013 growing seasons at six sites each year within the Intermountain PNW (Table 1; Figure 1). Four sites were replicated across years. Two sites were relocated in the second growing season because of resource constraints (Table 1). In each year, however, two sites were located in timothy hay, CRP, and rangeland. We established monitoring plots at each site within natural infestations of $V$. dubia. Ten plots $\left(400 \mathrm{~cm}^{2}\right)$ were permanently marked at $0.5-\mathrm{m}$ intervals along a $6-\mathrm{m}$ transect. A weather station was also established on the transect and a data logger (EM50, Decagon Devices) was used to take hourly measurements of precipitation (ECH2O, Decagon Devices) and ambient air temperature $1.33 \mathrm{~m}$ above the soil surface $(\mathrm{ECH} 2 \mathrm{O}-\mathrm{ECT}$; Decagon Devices). Soil moisture (\%VWC) and soil temperature $(\mathrm{C})$ were recorded with soil moisture probes that were installed at a $2.5-\mathrm{cm}$ soil depth and positioned upslope and downslope of the transect. Data were collected hourly, periodically downloaded, and quality control checked using the nearest regional weather station before use for data analysis.

Field plots were established each year by early to midSeptember before the first fall precipitation and visited weekly to biweekly during the fall growing season and approximately biweekly during the spring growing season. Ventenata dubia seedling emergence was quantified and then controlled with glyphosate at a $5 \%(\mathrm{v} / \mathrm{v})$ spray solution. Litter residue from the previous growing season was removed and replaced if required for density counts. The most advanced phenological stage of emerged $V$. dubia plants was recorded using the methods of Moore et al. (1991) in quadrats $\left(400 \mathrm{~cm}^{2}\right)$ positioned on the opposite side of the transect relative to the seedling emergence plots. Moore et al. (1991) describe a comprehensive system for quantifying the phenological development of perennial grasses using a continuous numerical index that can be used to develop quantitative relationships. This system concentrates on transitions from five primary growth stages of individual grass shoots (germination, vegetative, elongation, reproductive, and seed ripening) and can be utilized for monitoring annual grass phenology. We confined our growth stage observations from the fall vegetative stage of $V$. dubia seedlings to the hard dough seed ripening stage.

We calculated cumulated GDDs for each site and year using the model

$$
\begin{aligned}
\text { GDD }= & {[(\text { Daily Max TempDaily Min Temp }) / 2] } \\
& - \text { Base Temp }
\end{aligned}
$$

where daily max and min temperatures $(\mathrm{C})$ were measured at a $2.5-\mathrm{cm}$ soil depth averaged across two soil probes, and base temperature was $7 \mathrm{C}$. The base temperature was derived from our germination experiments on temperature (5 to $29 \mathrm{C}$ ) described in detail in the proceeding results 
section; germination of $V$. dubia seed did not occur below a test temperature of $8.6 \mathrm{C}$. Preliminary germination trials did not identify an upper temperature threshold. Consequently, the upper threshold of downy brome (30 C) was utilized (Thill et al. 1984).

Cumulative seedling emergence (\%) was plotted against cumulative GDDs and nonlinear models were fitted to the data for each site by year and analyzed using a nonlinear regression model of the form

$$
E=C /\left\{1+e\left[-b_{1}\left(G D D-b_{0}\right)\right]\right\}
$$

where $E$ is relative cumulative germination expressed as a percentage, $G D D$ is cumulative growing degree days (Equation 2), $C$ is a constant value of 1 , and $b_{0}$ and $b_{1}$ are estimated parameters, with $b_{0}$ estimating mean seedling emergence time (days to $50 \%$ of total seedling emergence per year) and $b_{1}$ estimating the relative slope around the inflection point. Cumulative germination was numerically transformed to a scale of 0 to $100 \%$ by dividing cumulative germination by the total number of seedlings emerged over the entire growing season for a given population. As a result, cumulative germination percentages were adjusted to a common scale for comparison of seedling emergence rates among populations (Hardegree and Van Vactor 2000). Calculation of cumulative GDD began after $\%$ VWC was greater than the estimated permanent wilting point (PWP) for silt loam soils (11\%) using the relationship between soil \%VWC, water potential, and soil texture described in Saxton and Rawls (2006). Seedling emergence patterns among habitat types (hay, CRP, rangeland), pooled across sites within system, were compared using the residual sums of squares reduction test for each year of the study.

Cumulative GDDs and Julian days at which $V$. dubia stem elongation and anthesis occurred were compared across perennial grass habitats. Transitions to stem elongation and anthesis stages were identified as the cumulative GDD and Julian days at the midpoint between biweekly sampling periods at which the given transition occurred. Cumulative GDDs were started on the date at which seedling emergence first occurred in the fall for each adjacent seedling emergence plot. Stem elongation and anthesis transitions were subjected to analysis of variance using a mixed model with habitat type as a main effect and with year and site as random effects. Data were natural log-transformed to achieve homogeneity of variance. Treatment means were separated using Fisher's LSD $(\mathrm{P}<0.05)$. Results are presented using untransformed treatment means.

\section{Results and Discussion}

In Vitro Germination Experiments. The length of afterripening significantly influenced $V$. dubia germination patterns (Table 2). Freshly harvested $V$. dubia seeds, collected in early July, did not germinate after $48 \mathrm{~d}$, and total cumulative germination was $<1 \%$ after $78 \mathrm{~d}$ of incubation. Germination was first recorded after $13 \mathrm{~d}$ of incubation for seeds stored for $30 \mathrm{~d}$. Total cumulative germination was $23,62,71$, and $64 \%$ at $70 \mathrm{~d}$ of incubation for $V$. dubia seed subjected to dry storage intervals of 30 , 60,90 , and $120 \mathrm{~d}$ after harvest, respectively. Germination rates (seeds $\mathrm{d}^{-1}$ ) increased as the after-ripening interval increased, and mean germination time (days to $50 \%$ total germination) ranged from 7 to $14 \mathrm{~d}$ across after-ripening intervals. Cold stratification at $5 \mathrm{C}$ for 5 and $10 \mathrm{~d}$ resulted in significant differences in total cumulative germination and germination rates compared with $V$. dubia seed that were maintained at room temperature before incubation (Table 2). Total cumulative germination of $V$. dubia seed stored at room temperature was $87 \%$, and mean germination time was $10.7 \mathrm{~d}$. In comparison, cold stratification for 5 and $10 \mathrm{~d}$ resulted in 28 and $35 \%$ total cumulative germination, respectively, and mean germination time was 39.9 and $35.0 \mathrm{~d}$, respectively. Germination patterns were minimally influenced by seed aging in dry storage (Table 2). Total cumulative germination of $V$. dubia seeds was $87.5,86.0,81.8$, and $81.5 \%$ after 4,18 , 30 , and 42 mo of dry storage, respectively (Table 2). Although low variance across replicates resulted in statistical differences, mean germination time differed by only several days across seed-aging intervals, ranging from 11 to $17 \mathrm{~d}$.

When subjected to temperatures between 5.0 and $7.8 \mathrm{C}$, nondormant $V$. dubia seed had not germinated after $42 \mathrm{~d}$ in each $V$. dubia test population (Figure 2). Germination occurred in only one population at $8.6 \mathrm{C}$ and was minimal ( $1 \%$ total germination). Each test population germinated across a wide range of temperatures (9.4 to $29.2 \mathrm{C}$ ). Populations differed in germination rate and mean germination time across each test temperature $(\mathrm{P}<$ 0.05 ). Total cumulative germination varied among replicates and populations, particularly at lower temperature regimes (9.4 to $12.2 \mathrm{C})$. Consequently, few differences in total cumulative germination among populations were detected across test temperatures. A maximum temperature beyond which germination ceased was not observed among populations. The optimum temperature, which would allow for the maximum germination in the shortest time, ranged from 23.3 to $29.2 \mathrm{C}$ among populations. At these temperatures, total cumulative germination ranged from 76 to $99 \%$ and mean germination time ranged from 7 to $13 \mathrm{~d}$.

Seed Bank Persistence. One month after burial, a significant portion of the artificial seed bank was lost to germination; total germination was 82 and $79 \%$ at burial depths of 2 and $8 \mathrm{~cm}$, respectively (Table 3 ). Less than $1 \%$ of the seed bank recovered 1 mo after burial had not germinated but was persistent, or germinable, at both 
Table 2. Parameter estimates for nonlinear models of cumulative $V$. dubia germination as a function of time (d). Models describe the effects of after-ripening period (d), cold stratification period (d) at $5 \mathrm{C}$, and seed aging period (mo). Parameter estimates include mean germination time $\left(b_{0}, \mathrm{~d}\right)$ and germination rate $\left(b_{1}\right.$, seeds $\left.\mathrm{d}^{-1}\right)$. Total cumulative germination (mean $\%$ and $95 \%$ confidence interval [CI]) was used for the asymptote of nonlinear models.

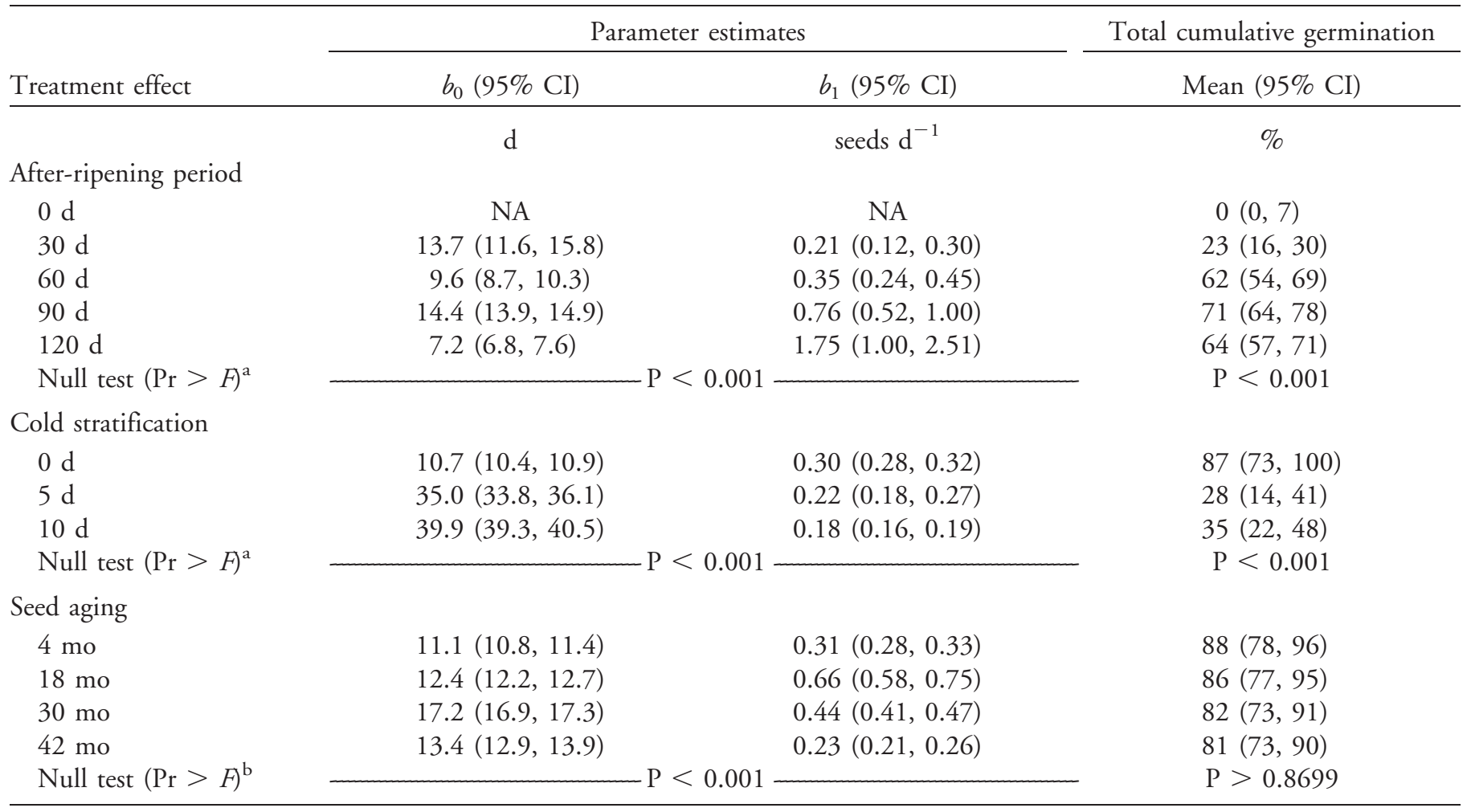

${ }^{a}$ Null test for germination rate $\left(b_{0}\right.$ and $\left.b_{1}\right)$ is $\operatorname{Pr}>F$ : reduced model (w/ pooled populations) vs. full model (by population).

${ }^{\mathrm{b}}$ Null test for total germination is $\operatorname{Pr}>F$ using Fisher's LSD $(\mathrm{P}<0.05)$ to separate treatment means.

burial depths. The remaining fraction (16 to 17\%) of the seed bank was lost to mortality. At subsequent retrieval dates, seed bank persistence was not significantly ( $\mathrm{P}<$ 0.05 ) influenced by burial depth (Table 3 ). However, we found a small but measureable $(<1 \%$ of seed bank) level of seed persistence at the 2 -cm depth 13,25 , and 37 mo after burial, whereas no seed persistence was observed at the 8 -cm depth. By 49 mo after burial, we found no seed persistence across the study.

Litter Effects on Seedling Emergence and Survival. The effect of increasing amounts of $V$. dubia litter on seedling emergence and density over the fall growing period was markedly different across years (Figure $3 ; 196 \mathrm{~g} \mathrm{~m}^{-2}$ treatment not shown because of lack of associated environmental data). No differences in seedling emergence among the 196 and $392 \mathrm{~g} \mathrm{~m}^{-2}$ litter treatments were observed across years. In 2011, the presence of litter (98, 196 , and $392 \mathrm{~g} \mathrm{~m}^{-2}$ ) resulted in significantly greater seedling emergence and higher seedling survival than the no-litter control. In comparison, $V$. dubia seedling density declined over the fall growing season in the no-litter control, and trends suggest that seedling survival declined slightly in the $98 \mathrm{~g} \mathrm{~m}^{-2}$ litter treatment. In 2012, the $392 \mathrm{~g} \mathrm{~m}^{-2}$ litter treatment resulted in significantly greater seedling densities than the no-litter control and the $98 \mathrm{~g} \mathrm{~m}^{-2}$ litter treatment, which did not differ from each other, at the first and second observations after initial seedling emergence occurred. However, by the last observation date, seedling densities did not differ between litter treatments.

Environmental trends in the upper soil profile $(2.5 \mathrm{~cm}$ depth) may explain, in part, differences in litter effects on seedling emergence and survival across years (Figure 3). In 2011, soil moisture levels were beneath the PWP (11\% VWC) in the no-litter control for a greater number of days in the fall growing season than the 98 and $392 \mathrm{~g} \mathrm{~m}^{-2}$ litter treatments. In 2012, soil moisture levels were above the PWP in the no-litter control for a longer period of time compared with 2011 because of greater cumulative precipitation. Soil moisture conditions, as measured by the number of days below the PWP, did not differ appreciably among litter treatments in the 2012 experiment. Additionally, litter treatments resulted in fewer 


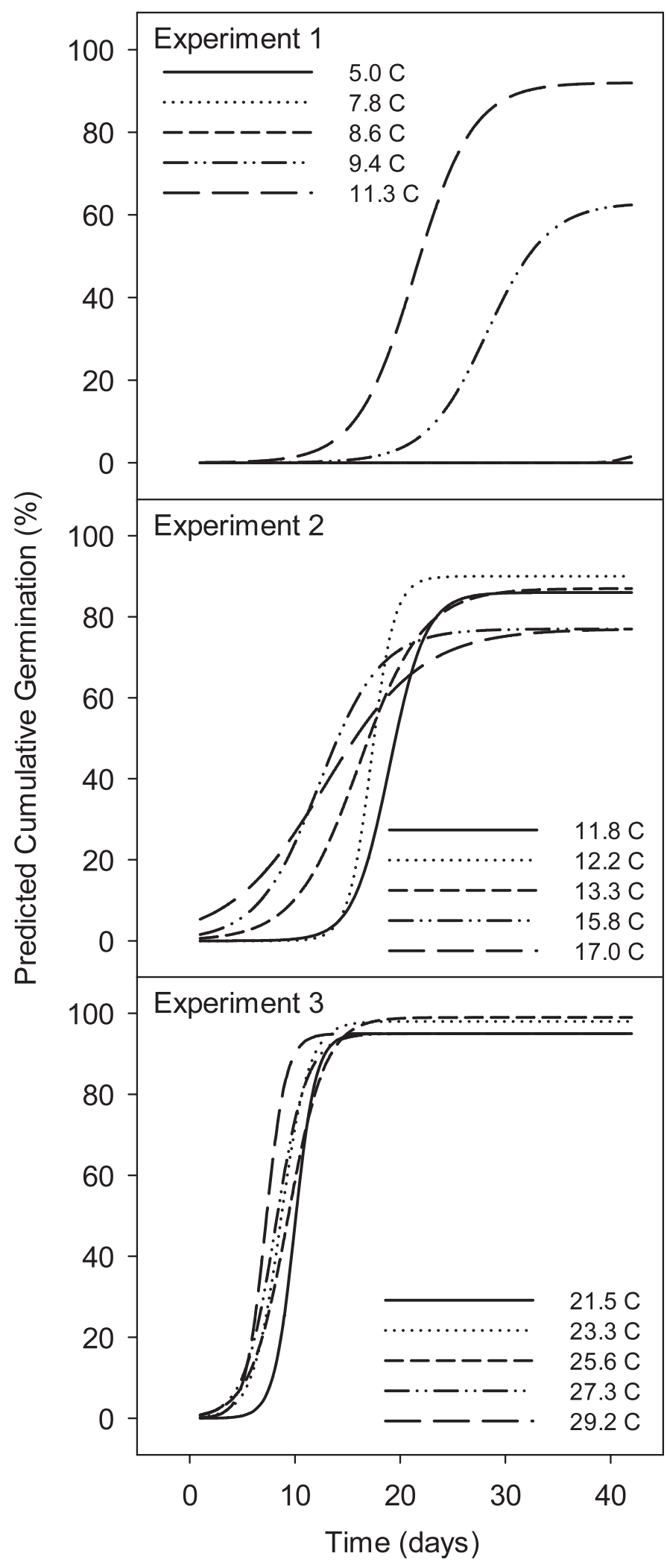

Figure 2. Predicted cumulative germination (\%) response of nondormant $V$. dubia seed as a function of time (d) across constant temperatures ranging from 5.0 to 29.2 C. Temperatures were tested across three sequential experiments. Germination response curves are pooled across five $V$. dubia test populations. number of days in which the upper soil profile was frozen compared with the no-litter control in both years (Figure 3). Consequently, variable seedling emergence and survival trends across years can likely be attributed to the mediation effects of litter on soil moisture and temperature in the upper soil profile.

In the 2012-2013 study, flowering plant densities were significantly $(\mathrm{P}=0.0065)$ greater $(1,621 \pm 133$ plants $\mathrm{m}^{-2}$ ) in the high-litter treatment than the no-litter control $\left(817 \pm 133\right.$ plants $\left.\mathrm{m}^{-2}\right)$, indicating that mortality of overwintering seedlings approached $50 \%$ in the no-litter control, whereas mortality of seedlings due to environmental stress or intraspecific competition was negligible in the high-litter treatment. However, we observed significantly greater $(\mathrm{P}=0.0137)$ tillering in the no-litter control $\left(2.59 \pm 0.16\right.$ tillers plant $\left.^{-1}\right)$ compared with the high-litter treatment $\left(1.6 \pm 0.16\right.$ tillers plant $\left.^{-1}\right)$, which resulted in greater seed production per plant in the no-litter control. As a result, litter effects on total seed production on an area basis were not observed $(\mathrm{P}=0.1385)$. Seed production ranged from $30,298 \pm 5,773$ seeds $\mathrm{m}^{-2}$ in the no-litter control to $43,429 \pm 5,773$ seeds $\mathrm{m}^{-2}$ in the high-litter treatment. These results suggest that a plastic growth habit enables high levels of reproduction in the absence of competition or resource constraints.

Seedling Emergence and Phenological Development Patterns. Seedling emergence models differed $(P<0.001)$ among perennial grass habitats within years, and among years within habitats (Figure 4). We interpolated 1, 50, and $95 \%$ cumulative seedling emergence from our predictive models to compare GDDs to calendar dates across sites and years, which provides greater understanding of seedling emergence patterns as it relates to management strategies among production systems (Table 4). Initial $V$. dubia seedling emergence (1\%) occurred between 2 and 42 GDDs, which corresponded to a 3-wk period in October across sites and years. This consistency among sites and years suggests that cumulative precipitation may act as a useful indicator of the onset of $V$. dubia seedling emergence. The amount of cumulative precipitation necessary to exceed the PWP was 1.30 to $2.25 \mathrm{~cm}$ across sites and years (Table 4). Mean seedling emergence (50\%) occurred between 33 and 94 GDDs, which corresponded to an approximate 4-wk period between mid-October and mid-November across sites and years. In relation to seedling emergence periodicity, the greatest observed differences among models across sites and years occurred at the time of $95 \%$ cumulative seedling emergence. Across CRP sites and years, $95 \%$ of seedling emergence occurred within the fall growing season, and seedling emergence during the spring growing season was negligible. Alternatively, greater seedling emergence during the spring growing season was observed in timothy hay systems across 
Table 3. Effect of $V$. dubia seed burial depth on seed bank fate 1 mo after burial and on seed bank persistence in proceeding years. Means pooled across sites are followed by $95 \%$ confidence intervals in parentheses.

\begin{tabular}{|c|c|c|c|c|c|c|c|c|}
\hline \multirow[b]{2}{*}{ Burial depth } & \multicolumn{4}{|c|}{ Seed fate $1 \mathrm{mo}$ after burial } & \multicolumn{4}{|c|}{ Seed bank persistence by months after burial } \\
\hline & Germinated & Persistent & & Lost & $13 \mathrm{mo}$ & 25 mo & $37 \mathrm{mo}$ & $49 \mathrm{mo}$ \\
\hline $\mathrm{cm}$ & & $\%$ & & - & L & $\%$ & r & \\
\hline 2 & $82 \quad(64,95)$ & $<1 \quad(0,4)$ & 17 & $(7,30)$ & $<1 \quad(0,1)$ & $<1 \quad(0,1)$ & $<1 \quad(0,1)$ & 0 \\
\hline 8 & $79 \quad(62,93)$ & $<1 \quad(0,4)$ & 16 & $(7,29)$ & $0 \quad(0,1)$ & $0 \quad(0,1)$ & $0 \quad(0,1)$ & 0 \\
\hline $\operatorname{Pr}>F^{a}$ & ns & ns & & ns & ns & ns & ns & ns \\
\hline
\end{tabular}

${ }^{a}$ ns $=$ Nonsignificant at $\mathrm{P}<0.05$ using Fisher's LSD.

sites and years; our models indicate that $95 \%$ of total seedling emergence occurred between late March and early April. Cumulative spring seedling emergence ranged from 4 to $13 \%$ in timothy hay habitats. Within rangeland sites, the proportion of seedling emergence that occurred in the fall and spring differed across years, where $95 \%$ of cumulative seedling emergence occurred within the fall growing season in 2012 and in late March in 2013. The difference in seedling emergence patterns between years in

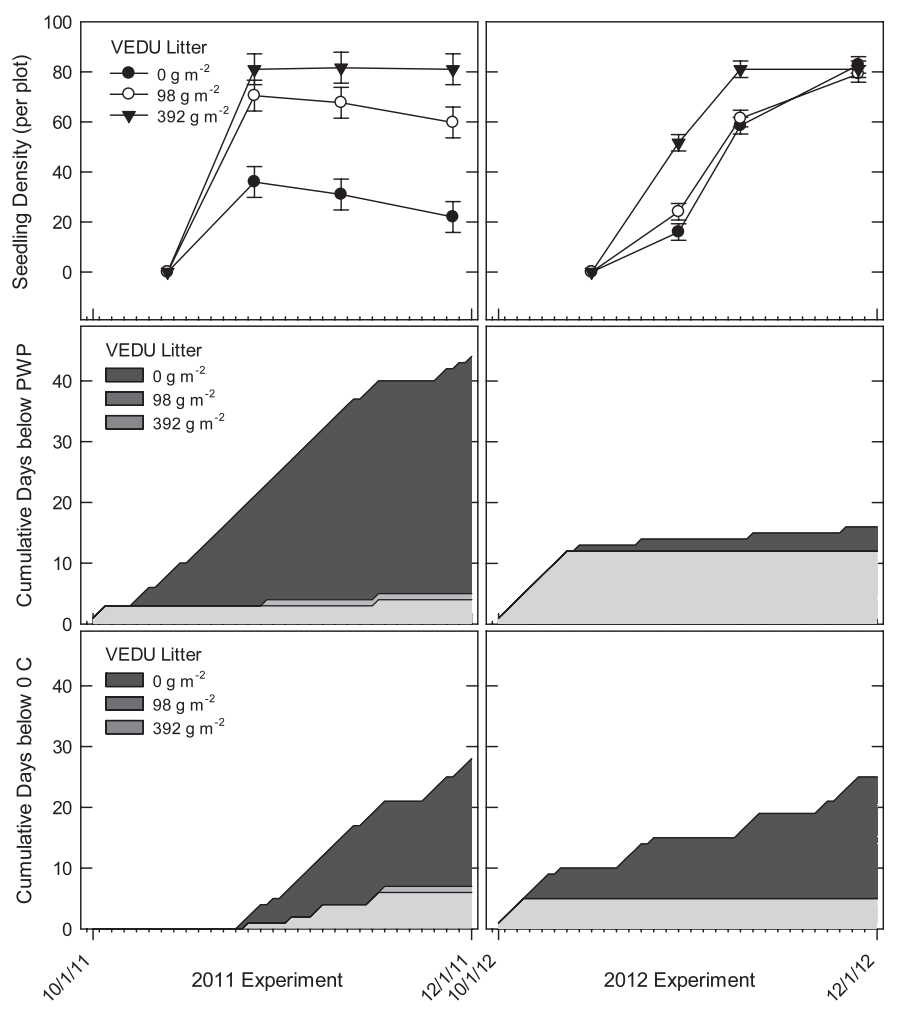

Figure 3. The effect of $V$. dubia (VEDU) litter levels (0, 98, $392 \mathrm{~g} \mathrm{~m}^{-2}$ ) on $V$. dubia seedling density (per plot), the cumulative number of days that soil moisture (\% volume water content; VWC) was below the permanent wilting point (PWP; $<11 \%$ VWC) in the upper soil profile $(2.54 \mathrm{~cm})$, and the number of days in which the upper soil profile temperature is below 0 C for 2011-2012 and 2012-2013 experiments. rangeland systems is likely a function of differing precipitation patterns (Figure 5). Soil moisture, as measured by the number of days the upper soil profile was below the PWP (11\% VWC), was considerably lower in late fall and winter of 2012 compared with 2013. Soil temperatures did not differ appreciably between years.

As a function of GDDs, the phenological transition to stem elongation was similar among perennial grass habitats $(\mathrm{P}=0.8911)$, but the transition to anthesis differed ( $\mathrm{P}=$ 0.0044; Figure 6). Differences among habitat types at the phenological transition to anthesis corresponded to soil temperature differences among habitat types; timothy hay sites were comparably cooler, and CRP sites were generally warmer (Figure 5). However, when analyzed as a function of Julian days, phenological transitions to stem elongation and anthesis did not differ $(\mathrm{P}>0.05)$, which suggests that photoperiod regulates $V$. dubia phenological transitions related to reproductive timing. The average date at which stem elongation occurred ranged from May 2 to May 27 across sites and years. The average date at which anthesis

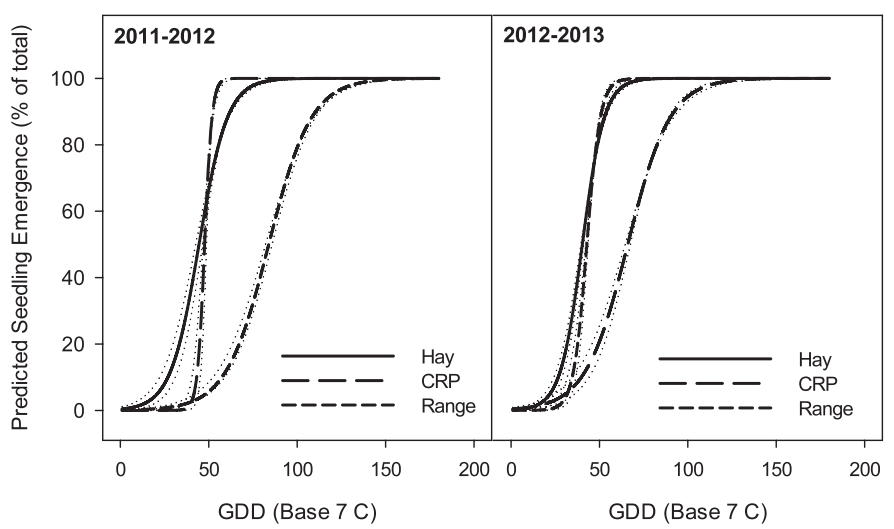

Figure 4. Predicted cumulative seedling emergence (\%) of $V$. dubia as a function of growing degree days (GDD; base $7 \mathrm{C}$ ) across three habitat types in 2011-2012 and 2012-2013 growing seasons. Dotted lines denote $95 \%$ prediction intervals. Cumulative GDDs were initiated after the permanent wilting point (11\% VWC) was exceeded. 
Table 4. Estimated cumulated growing degree days (GDD) and corresponding calendar date for 1, 50, and 90\% cumulative $V$. dubia seedling emergence for each study site and year. Cumulative GDDs were initiated after the permanent wilting point (11\% volumetric water content) was exceeded. The observed cumulative precipitation (Precip, $\mathrm{cm}$ ) at the permanent wilting point and the corresponding date are reported.

\begin{tabular}{|c|c|c|c|c|c|c|c|c|c|}
\hline \multirow[b]{2}{*}{ Site (by land use) } & \multirow[b]{2}{*}{ Year } & \multicolumn{2}{|c|}{ Permanent wilting point ${ }^{\mathrm{a}}$} & \multicolumn{6}{|c|}{ Ventenata seedling emergence $(\% \text { of total })^{\mathrm{b}}$} \\
\hline & & Precip & Date & $1 \%$ & $50 \%$ & $95 \%$ & $1 \%$ & $50 \%$ & $95 \%$ \\
\hline & & $\mathrm{cm}$ & & & -GDD & & & -Date - & \\
\hline \multicolumn{10}{|l|}{ Hay } \\
\hline \multirow[t]{2}{*}{ Usk, WA } & $2011-2012$ & 2.20 & Oct 11 & 26 & 49 & 65 & Oct 16 & Oct 23 & Mar 25 \\
\hline & 2012-2013 & 2.20 & Oct 22 & 2 & 35 & 58 & Oct 24 & Nov 7 & Mar 26 \\
\hline \multirow[t]{2}{*}{ Harvard, ID } & $2011-2012$ & 1.68 & Oct 10 & 24 & 63 & 120 & Oct 12 & Oct 20 & Apr 10 \\
\hline & $2012-2013$ & 1.40 & Oct 13 & 18 & 44 & 59 & Oct 15 & Nov 1 & Mar 19 \\
\hline \multicolumn{10}{|l|}{ CRP } \\
\hline \multirow[t]{2}{*}{ Moscow, ID } & $2011-2012$ & 2.20 & Oct 6 & 24 & 76 & 106 & Oct 9 & Oct 18 & Oct 23 \\
\hline & 2012-2013 & 1.70 & Oct 12 & 2 & 71 & 119 & Oct 14 & Oct 30 & Dec 2 \\
\hline Worley, ID & $2011-2012$ & 2.35 & Oct 11 & 35 & 47 & 54 & Oct 20 & Oct 24 & Nov 1 \\
\hline Deary, ID & 2012-2013 & 1.60 & Oct 15 & 42 & 58 & 68 & Oct 19 & Oct 29 & Oct 31 \\
\hline \multicolumn{10}{|l|}{ Rangeland } \\
\hline \multirow[t]{2}{*}{ Anatone, WA } & 2011-2012 & 2.30 & Oct 6 & 3 & 78 & 120 & Oct 11 & Oct 23 & Mar 28 \\
\hline & 2012-2013 & 1.40 & Oct 15 & 35 & 41 & 50 & Oct 29 & Oct 31 & Nov 2 \\
\hline Enterprise, OR & 2011-2012 & 1.30 & Oct 6 & 25 & 90 & 127 & Oct 11 & Oct 24 & Mar 15 \\
\hline Lewiston, ID & 2012-2013 & 2.05 & Oct 15 & 19 & 43 & 56 & Oct 17 & Oct 29 & Nov 3 \\
\hline Ashwood, OR & 2012-2013 & NA & Nov 1 & 2 & 36 & 63 & Nov 3 & Nov 18 & Feb 8 \\
\hline \multirow[t]{2}{*}{ Range } & Min & 1.30 & Oct 6 & 2 & 35 & 50 & Oct 9 & Oct 18 & Oct 23 \\
\hline & $\operatorname{Max}$ & 2.35 & Nov 1 & 42 & 90 & 127 & Nov 3 & Nov 18 & Apr 10 \\
\hline
\end{tabular}

${ }^{a}$ Measured soil volume water content was used to estimate permanent wilting point for silt loam (11\%), as described by Saxton and Rawls (2006), which was utilized as starting point for GDD accumulation. Cumulated precipitation (cm) and calendar date at which permanent wilting point is reached is shown for each site. NA, not available; Oct, October; Mar, March; Apr, April; Nov, November; Feb, February; Min, minimum; Max, maximum.

${ }^{\mathrm{b}}$ Predicted cumulated growing degree days (base temperature $=7 \mathrm{C}$ ) for 1,50 , and $95 \%$ cumulative seedling emergence and the corresponding calendar date.

occurred ranged from June 9 to June 29 across sites and years.

Summary of Life History Patterns. In vitro germination trial results suggest that the dry after-ripening period required for dormancy loss of $V$. dubia seed does not exceed $30 \mathrm{~d}$. However, germination rates and total cumulative germination were highest after a 90-d afterripening period, which suggests that dormancy breakdown increases as after-ripening length increases up to approximately $90 \mathrm{~d}$. After-ripening is a physiological mechanism that reflects an adaptation to seasonal drought and dry soils for winter annual species, whereby seeds remain conditionally dormant when temperatures are typically high and soil conditions are dry until more favorable conditions for survivorship occur in autumn. In our field studies, soil moisture levels increased after precipitation in early to midOctober across habitat types and years, which align with peak dormancy breakdown $(90 \mathrm{~d})$ patterns observed in the germination trials. Ventenata dubia seedlings emerged over a range of temperature conditions throughout October and November, which aligns with the results of our in vitro experiments showing germination over a range of test temperatures (9 to 29 C) after a 4-mo after-ripening period. Although germination rates differed among populations from habitats, the optimal temperature range for germination among populations did not differ dramatically (23 to 29 C) in germination experiments.

Variable germination patterns among different habitat types can be a function of differing environmental conditions during the after-ripening process. For example, conditional dormancy of harvested downy brome seed can be overcome either by prechilling (5 C) moistened seed (Steinbauer and Grigsby 1957) or through exposure of dry seed to high temperatures ( $>30$ C; Thill et al. 1980). As a result, downy brome germination trends vary among different habitats and among populations from similar habitats across western North America (Meyer et al. 1997). 


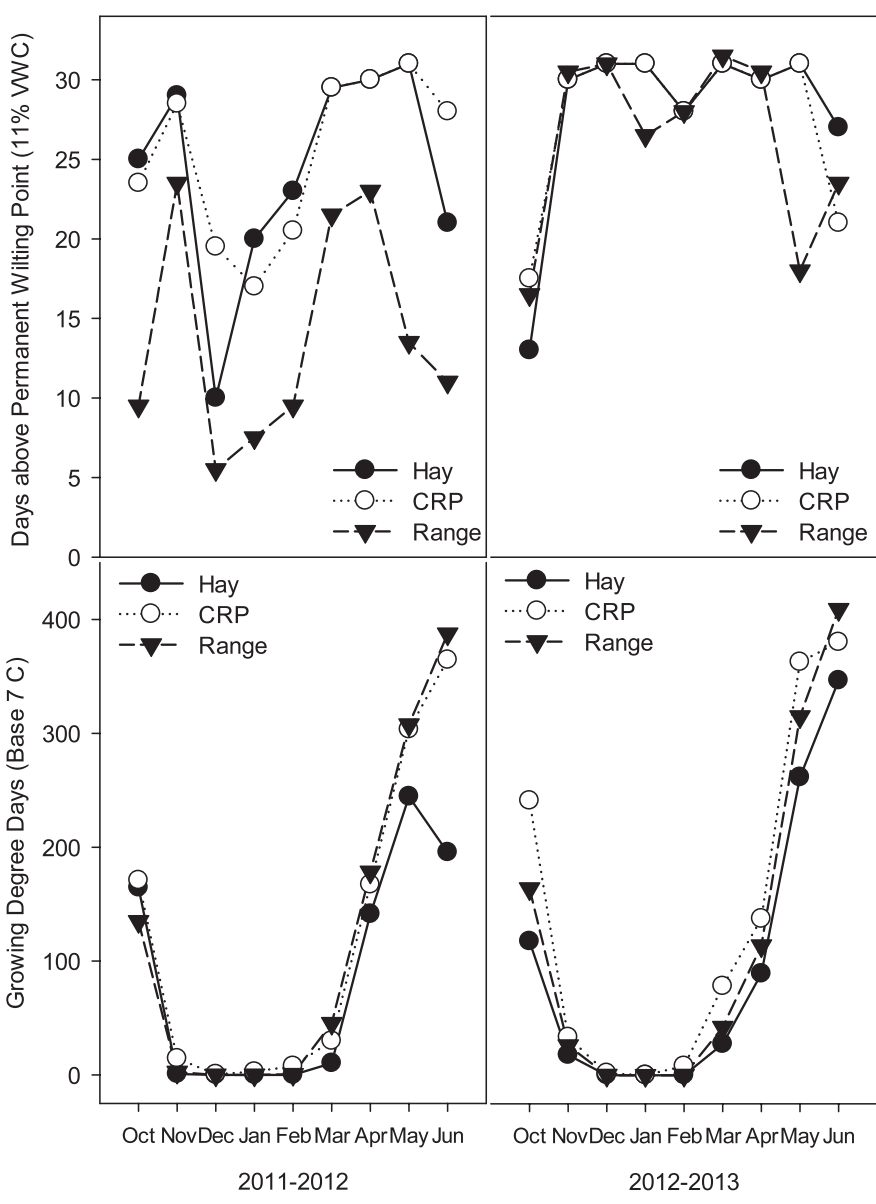

Figure 5. Days above the permanent wilting point and cumulative growing degree days per month in hay, Conservation Reserve Program (CRP) land, and rangeland habitat types for the 2011-2012 and 2012-2013 growing seasons. Environmental data is averaged across study sites within habitat types.

For example, germination of downy brome is often observed in the field in mid-August after sufficient summer rains and when soil temperatures are high. This pattern of seedling emergence is attributed to accelerated afterripening induced by high temperatures, which rapidly reduces postharvest dormancy and broadens the range of temperatures at which germination can occur (Thill et al. 1980). To our knowledge, $V$. dubia seedling emergence has not been similarly observed in mid-August within the Intermountain PNW. Greater investigation is needed to determine how exposure to variable temperature and moisture conditions during after-ripening periods influence $V$. dubia germination and seedling emergence patterns.

The results of our cold stratification experiment, coupled with no observed germination at temperatures below $7 \mathrm{C}$ in temperature experiments, suggest that nondormant $V$. dubia seeds may be environmentally induced into secondary dormancy when soil temperatures fall below optimal conditions for germination. The use of $7 \mathrm{C}$ as a

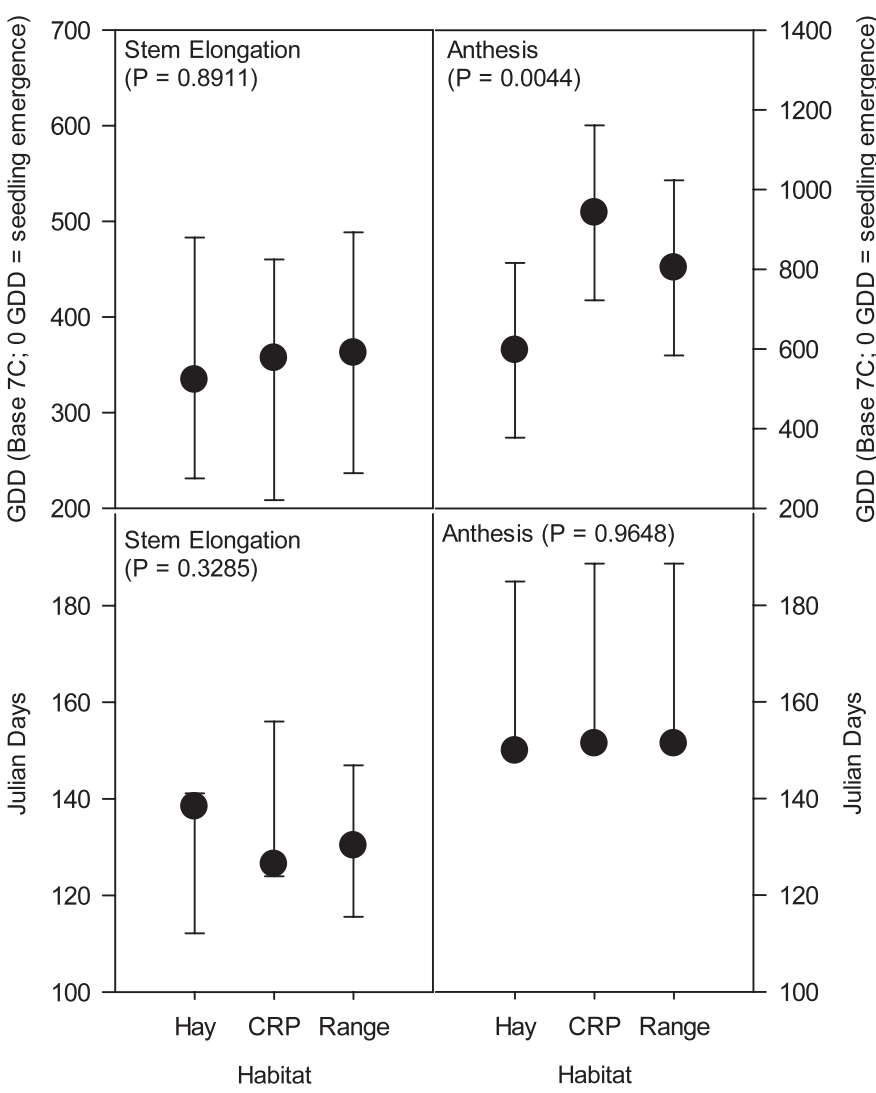

Figure 6. Effect of cumulative growing degree days (GDD) and Julian days on $V$. dubia phenological transitions to stem elongation and anthesis across hay, Conservation Reserve Program (CRP) land, and rangeland habitat types. Error bars denote $95 \%$ confidence intervals.

base temperature in predictive models of seedling emergence based on GDD produced further support for this secondary dormancy pattern. At this base temperature, cumulative GDDs declined sharply in November and were close to zero in December, January, and February. Seedling emergence rates declined in November and were negligible in the following 3 mo across study sites. Similarly to dormancy breakdown trends, the effect of cold stratification on germination response can differ among populations in variable habitats (Milberg and Andersson 1998). Further investigation is needed to determine how the length of cold stratification influences $V$. dubia secondary dormancy characteristics and spring seedling emergence patterns.

Our results suggest that $V$. dubia seed would likely maintain its ability to germinate when transported as a hay or dry-storage contaminant over longer distances and periods of time. The age of nondormant $V$. dubia seed stored under dry conditions did not significantly influence germination response; total germination $(81 \%)$ and mean germination time $42 \mathrm{mo}$ after harvest was comparable to the germination response $4 \mathrm{mo}$ after harvest. Maintenance 
of seed viability over several years is an adaptive trait of species in arid environments that are prone to periods of drought. As seed deteriorates with age, however, delayed germination and losses in seedling vigor can result in a fitness cost, reducing plant competitive ability, as shown in a study of $B$. tectorum across variable habitats (Rice and Dyer 2001).

Seed burial depth can alter environmental factors (i.e., soil temperature, soil temperature fluctuation, and soil water potential) that are critical to dormancy breakdown and germination (Forcella et al. 2000). Our seed bank persistence study showed that $V$. dubia seed bank fate patterns were similar at a 2-and 8-cm soil depth in the first growing season after seed burial in a prairie grassland habitat. However, a small percentage $(<1 \%)$ of the initial seed bank remained germinable up to $3 \mathrm{yr}$ after burial at the $2-\mathrm{cm}$ depth, but no germinable seed were detected at the $8-\mathrm{cm}$ depth $1 \mathrm{yr}$ after burial. These trends are similar to field observations of $B$. tectorum seed, which rarely persists $(<1 \%$ of total seed bank) beyond $2 \mathrm{yr}$ after seed rain in the Intermountain West (Smith et al. 2008). A small fraction of seed that persist in the seed bank for several years can have significant implications for population maintenance and recruitment in disturbed habitats, particularly for highly fecund species (Harper 1977). On the basis of our studies, annual $V$. dubia seed rain can range from 30,000 to 43,000 seeds $\mathrm{m}^{-2}$ in the absence of competition. Further investigation is needed to determine what environmental or biological factors contribute to $V$. dubia seed bank persistence trends across varying soil depths and soil types, as well as to identify seed burial depths at which seedling emergence is precluded because of the lack of germination cues or through fatal germination during pre-emergence seedling elongation. Greater understanding of these factors would help determine how cultivation may be used as a management tactic in pasture, hay, and CRP lands.

Within low-disturbance perennial grass systems, $V$. dubia seed is primarily found at or near the soil surface. Surface residues have been shown to increase germination and seedling establishment at the soil surface (Harper 1977). Residue effects on population- and communitylevel processes are a function of complex factors that include residue quality, allelopathy, seed depth in soil, soil type, and environmental conditions (Facelli 1991) and have been shown to be particularly important in exotic winter annual grass invasions (Evans and Young 1970; Sheley et al. 2009; Sperry et al. 2006; Young 1992). The results of our litter residue study suggest that the presence of $V$. dubia litter enables maintenance of $V$. dubia populations during years in which environmental conditions are less suitable for seedling emergence and survival in late fall. Seedling survivorship is an important demographic process that is closely linked to the periodicity of seedling establishment (Mack and Pyke 1983). Observed population recruitment trends also suggest that the effect of litter on seedling survivorship may be minimized by $V$. dubia's ability to maximize reproduction through increased tillering if resources are not limited by competition. Greater study is needed to characterize the effect of $V$. dubia litter on ecological processes that lead to weed invasion at a community scale.

Patterns of $V$. dubia seedling emergence observed across a $300-\mathrm{km}$ gradient and several habitat types were similar, primarily differing in the proportion of total seedling emergence that occurred in the spring growing season. Late summer precipitation is normally too episodic to maintain soil moisture above the PWP for any length of time within the Intermountain PNW. Consequently, it is likely that $V$. dubia populations from different habitat types across the region were exposed to similar dry after-ripening conditions that differ only in temperature. Similar environmental conditions during dormancy breakdown may, in part, explain the similar patterns of initial $(1 \%)$ and mean $(50 \%)$ seedling emergence among habitat types. Mean seedling emergence ( $50 \%$ of total emergence) ranged from 33 to 94 GDDs across sites and years. The soil moisture level corresponding to the PWP (11\% VWC in silt loams) was a useful threshold for predicting $V$. dubia seedling emergence as a function of GDDs. Post hoc analysis suggests that soil temperature and moisture patterns can explain, in part, variation in spring seedling emergence. We observed minimal seedling emergence during the spring in CRP lands and comparatively higher levels of seedling emergence during spring in both rangeland and timothy hay systems. Rangeland systems are more likely to maintain higher soil temperatures and receive episodic fall precipitation, resulting in periods of low soil moisture relative to hay and CRP systems (Figure 5). Such conditions likely contributed to the variable patterns of seedling emergence we observed from year to year, in which spring seedling recruitment was proportionally higher in 2011-2012 when precipitation was comparatively lower. Within hay systems at more northerly latitudes, soil temperatures declined more rapidly in the fall and increased more slowly in the spring (Figure 5). Consequently, it is more likely that soil temperatures will be suboptimal $(<7 \mathrm{C})$ for germination after adequate soil moisture occurs in the fall, which may result in a greater proportion of spring seedling recruits that were induced into secondary dormancy.

Predictive models of seedling emergence generated from our studies may be used to improve performance of herbicide control strategies for $V$. dubia in the Intermountain PNW. In general, the most effective period of herbicide applications for winter annual grass weeds is normally during the fall months, but late fall environmental conditions can make herbicide applications during this critical period difficult. Alternatively, spring herbicide 
applications occur after weed competition for early spring nutrients and moisture and is further complicated by variable tolerance of perennial grass species to common annual grass herbicides such as imazapic (Kyser et al. 2007), propoxycarbazone-sodium [2-[(4-methyl-5-oxo-3propoxy-1,2,4-triazolin-1-yl)carbamidosulfonyl]benzoic acid methyl ester sodium salt] (Sbatella et al. 2011), and sulfosulfuron (Monaco and Creech 2004). Our models suggest that delaying applications to late fall after the primary seedling emergence period would improve the performance of early postemergence applications, but full-season weed control that includes spring-emerging cohorts will depend on the soil residual properties of herbicide options. In addition, predictive models of phenological development transitions generated from our studies may improve the performance of several cultural control strategies. For example, local producers have attempted to mow large monoculture patches of $V$. dubia before seed set to decrease seed production in the following growing season, and hay producers have opted to harvest hay for silage before $V$. dubia seed production to manage infestations.

Our models of phenological development also provide several explanations for why $V$. dubia populations are increasing across different habitat types within the Intermountain PNW. In general, $V$. dubia plants remained in the vegetative growth stage at the two- to three-leaf stage (shedding older leaves) throughout the spring, with little to no increases in biomass, and did not transition to the stem elongation phase until mid-May. Within the Intermountain PNW, pasture-based livestock operations often utilize rangeland sites within canyon grasslands between early May and mid-June before moving livestock to summer pasture. Observed trends suggest that, beyond palatability differences, $V$. dubia would be minimally grazed in canyon grasslands compared with $B$. tectorum because of its vegetative growth habit and developmental rate during spring grazing season. Ventenata dubia anthesis occurred in mid-June and, with few exceptions, produced mature seed by early July. Hay harvest within the Intermountain PNW routinely occurs at the beginning of July and therefore likely contains mature $V$. dubia seed in hay bales that is then distributed at local to regional scales.

Conclusion. This collection of studies provides an initial understanding of $V$. dubia dormancy, germination, seedling emergence, and phenological development patterns within several habitat types in the Intermountain PNW, where it has becoming increasingly invasive. Although considerable gaps in the knowledge of $V$. dubia life history traits still exist, these studies provide a basis for future investigations of ecological processes that facilitate $V$. dubia invasions and should improve the development of integrated management strategies. Looking forward, further investigation is needed to determine how the observed variation in $V$. dubia life history characteristics influences invasion processes at population, community, and ecosystem scales within the Intermountain PNW. Finally, observations of $V$. dubia life history patterns and genetic variation in more extreme environments within and beyond this region will also be critical to understanding its invasion potential in the semiarid West.

\section{Acknowledgments}

The authors gratefully acknowledge Taylor Ortiz, Andrew Mackey, Hannah Tomlinson, Dallas Spellman, Dr. Gustavo Sbatella, Sasha Twelker, and Mark Stannard for their assistance with laboratory and field studies. This research was partially funded by a U.S. Department of Agriculture Western Sustainable Agricultural Research and Education grant [SW10-103].

\section{Literature Cited}

Barkworth ME, Capels KM, Long S Ventenata. Pages 683-684 in Flora of North America Editorial Committee, eds. Flora of North America North of Mexico. Volume 24, Magnoliophyta: Commelinidae (in part): Poaceae, part 1. New York and Oxford: Oxford University Press

Butler MD (2011) Rehabilitating Ventenata infested rangelands using herbicides in conjunction with bunchgrass seedings. Pages 108 in Proceedings of Western Society of Weed Science. Volume 64. Las Cruces, NM: Western Society of Weed Science

Evans RA, Young JA (1970) Plant litter and establishment of alien annual weed species in rangeland communities. Weed Sci 18: 697-703

Facelli JM (1991) Plant litter: its dynamics and effects on plant community structure. Bot Rev 57:1-32

Forcella F, Arnold RL, Sanchez R, Ghersa CM (2000) Modeling seedling emergence. Field Crop Res 67:123-139

Fountain B (2011) Producing timothy hay and managing for the impacts of Ventenata. Pages 107-108 in Proceedings of Western Society of Weed Science. Volume 64. Las Cruces, NM: Western Society of Weed Science

Hardegree SP, Van Vactor SS (2000) Germination and emergence of primed grass seeds under field and simulated-field temperature regimes. Ann Bot 85:379-390

Harper JP (1977) Population Biology of Plants. Chapter 5. New YorkLondon-San Francisco: Academic Press, 892 p

Holt JS, Orcutt DR (1996) Temperature thresholds for bud sprouting in perennial weeds and seed germination in cotton. Weed Sci 44: 523-533

Knezevic SZ, Evans SP, Blankenship EE, Van Acker RE, Lindquist JL (2002) Critical period for weed control: the concept and data analysis. Weed Sci 50:773-786

Kyser GB, DiTomaso JM, Doran MP, Orloff SB, Wilson RG, Lancaster DL, Lile DF, Porath ML (2007) Control of medusahead (Taeniatherum caput-medusae) and other annual grasses with imazapic. Weed Tech 21:66-75

Mack RN, Pyke DA (1983) Demography of Bromus tectorum: variation in time and space. J Ecol 71:69-93

McCloskey WB, Prather T, Lass LW (2011) Classification of annual versus perennial grasses in rangelands: a first step towards a landscape decision tool. Pages 110 in Proceedings of Western Society of Weed Science. Volume 64. Las Cruces, NM: Western Society of Weed Science 
Meyer SE, Allen PS, Becktead J (1997) Seed germination regulation in Bromus tectorum (Poaceae) and its ecological significance. Oikos 78: 475-485

Milberg P, Andersson L (1998) Does cold stratification level out differences in seed germinability between populations? Plant Ecol 134:225-234

Monaco TA, Creech JE (2004) Sulfosulfuron effects on growth and photosynthesis of 15 range grasses. J Range Manage 57:490-496

Moore KJ, Moser LE, Vogel KP, Waller SS, Johnson BE (1991) Describing and quantifying growth stages of perennial forage grasses. Agron J 83:1073-1077

Northam FE, Callihan RH (1985) Germination of four annual grass weeds at three temperatures. Moscow, ID: University of Idaho Weed Science Division Idaho Weed Control Report, Pp. 198-199

Nyamai PA, Prather TS, Wallace JM (2011) Evaluating restoration methods across a range of plant communities dominated by invasive annual grasses to native perennial grasses. Invasive Plant Sci Manag 4: 306-316

Patton JE, Northam FE, Callihan RH (1985) Ventenata dubia germination studies. Moscow, ID: University of Idaho Weed Science Division Idaho Weed Control Report, Pp. 196-197

Pavek P, Wallace JM, Prather TS (2011) Ventenata biology and distribution in the Pacific Northwest. Pages 107 in Proceedings of Western Society of Weed Science. Volume 64. Las Cruces, NM: Western Society of Weed Science

Rice KJ, Dyer AR (2001) Seed aging, delayed germination and reduced competitive ability in Bromus tectorum. Plant Ecol 155:237-243

Roach DA, Wulff RD (1987) Maternal effects in plants. Annu Rev Ecol Syst 18:209-236

Saxton KE, Rawls WJ (2006) Soil water characteristic estimates by texture and organic matter for hydrologic solutions. Soil Sci Soc Am J 70:1569-1578

Sbatella GM, Wilson RG, Enloe SF, Hicks C (2011) Propoxycarbazonesodium and imazapic effects on downy brome (Bromus tectorum) and newly seed perennial grasses. Invasive Plant Sci Manag 4:78-86

Sharma MP, Vanden Born WH (1978) The biology of Canadian weeds. 27. Avena fatua L. Can J Plant Sci 58:141-157
Sheley R, Vasquez E, Hoopes C (2009) Functional group responses to reciprocal plant litter exchanges between native and invasive plant dominated grasslands. Invasive Plant Sci Manag 2:158-165

Smith DC, Meyer SE, Anderson VJ (2008) Factors affecting Bromus tectorum seed bank carryover in Western Utah. Range Ecol Manag 61: 430-436

Sperry LJ, Belnap J, Evans RD (2006) Bromus tectorum alters nitrogen dynamics in an undisturbed arid grassland ecosystem. Ecology 87: 603-615

Steinbauer GP, Grigsby BH (1957) Field and laboratory studies on the dormancy and germination of the seeds of chess (Bromus secalinus L.) and downy bromegrass (Bromus tectorum L.) Weeds 5:1-4

Swanton CJ, Mahoney KJ, Chandler K, Gulden RH (2008) Integrated weed management: knowledge-based weed management systems. Weed Sci 56:168-172

Thill DC, Beck KG, Callihan RH (1984) The biology of downy brome (Bromus tectorum) Weed Sci 32(Suppl 1):7-12

Thill DC, Schirman RD, Appleby AP (1980) Influence of after-ripening temperature and endogenous rhythms on downy brome (Bromus tectorum) germination. Weed Sci 28:321-323

[USDA-NASS] U.S. Department of Agriculture National Agricultural Statistics Service (2013) CropScape-Cropland Data Layer. 2011. http://nassgeodata.gmu.edu/CropScape/. Accessed June, 2013

Wallace J, Prather T (2011) Management of Ventenata in pasture and CRP. Pages 109-110 in Proceedings of Western Society of Weed Science. Volume 64. Las Cruces, NM: Western Society of Weed Science

Xu S, Johnson-Maynard JL, Prather TS (2013) Earthworm density and biomass in relation to plant diversity and soil properties in a Palouse prairie remnant. Appl Soil Ecol 72:119-127

Young JA (1992) Ecology and management of medusahead (Taeniatherum caput-medusae ssp. Asperum [Simk.] Melderis). Great Basin Nat 52:245-252

Received May 7, 2014, and approved October 18, 2014. 